\title{
Treatment of anterior open bite by posterior maxillary segmental osteotomy and miniplates: a case report
}

\author{
Sung-Kwon Choi ${ }^{1}$ and Kyung-Hwan Kwon ${ }^{2 *}$ (D)
}

\begin{abstract}
Background: Anterior open bite is a challenging malocclusion to correct orthodontic treatment. Anterior open bite associated with over-erupted posterior teeth and long lower facial height should be treated by reduction of posterior dimension for esthetic results. Although the possibility of orthodontic treatment of an anterior open bite has increased with the introduction of skeletal anchorage, there are still cases requiring surgery for various reasons.

Case presentation: This case report covers an anterior open bite of a 25 -year-old man successfully treated with the posterior maxillary segmental osteotomy (PMSO) and miniplates. After the pre-surgical orthodontic treatment, the PMSO between canines and first premolars was performed under local anesthesia and miniplates were placed on the zygomatic buttress. As a result of 28 months of treatment, an impaction amount of $3.5 \mathrm{~mm}$ was obtained in the maxillary posterior teeth, and the facial esthetics improved at rest and smile.

Conclusion: The impaction of the posterior dentoalveolar segment using the PMSO can be a good treatment option in patients with anterior open bite showing long lower facial height.
\end{abstract}

Keywords: Anterior open bite, Posterior maxillary segmental osteotomy (PMSO), Skeletal anchorages, Miniplates

\section{Background}

Anterior open bite is a challenging malocclusion to treat orthodontically. It could result from various factors such as habits, tongue postures, airway obstruction, vertical skeletal growth problems, and temporomandibular joint disorders [1-3].

Anterior open bite is often associated with overerupted posterior teeth and long lower face height $[4,5]$. In this type of malocclusion, intrusive mechanics are required for optimal esthetic results. Before the introduction of skeletal anchorages, a reduction of the posterior vertical dimension can be achieved by orthognathic surgery. The intrusion of posterior teeth became possible by the use of skeletal anchorages. However, the

\footnotetext{
*Correspondence: denhouse@naver.com

${ }^{2}$ Department of Oral and Maxillofacial Surgery, College of Dentistry,

Wonkwang University, Iksan, Republic of Korea

Full list of author information is available at the end of the article
}

treatment duration and retention of the treatment results are still issues [6-8].

Posterior maxillary segmental osteotomy (PMSO) is a surgery for repositioning of the posterior dentoalveolar segment. It has been mainly used to make an intermaxillary space for the restoration of mandibular teeth $[9,10]$. In the area of orthodontics, the segmental surgery can be used to correct the transverse and vertical discrepancies of the maxilla $[11,12]$. The PMSO has advantages than orthodontic intrusion when there are many teeth to be intruded or when a large amount of intrusion is required.

This case report covers an anterior open bite of a 25year-old man successfully treated with the PMSO and miniplates.

\section{Case presentation}

A 25-year-old male patient visited our Department of Orthodontics with a chief complaint of anterior open

\section{Springer Open}

(c) The Author(s). 2020 Open Access This article is licensed under a Creative Commons Attribution 4.0 International License, which permits use, sharing, adaptation, distribution and reproduction in any medium or format, as long as you give appropriate credit to the original author(s) and the source, provide a link to the Creative Commons licence, and indicate if changes were made. The images or other third party material in this article are included in the article's Creative Commons licence, unless indicated otherwise in a credit line to the material. If material is not included in the article's Creative Commons licence and your intended use is not permitted by statutory regulation or exceeds the permitted use, you will need to obtain permission directly from the copyright holder. To view a copy of this licence, visit http://creativecommons.org/licenses/by/4.0/. 
bite. Clinical examination revealed a class I molar and canine relationship. The overjet and overbite were $1 \mathrm{~mm}$ and $-2 \mathrm{~mm}$, respectively, and open bite was limited only to the incisors. The exposure of maxillary anterior teeth in a smile was adequate, and lip competence could be achieved with some mentalis strain. Reverse smile arc and excessive exposure of mandibular teeth were observed in facial photographs (Fig. 1). The cephalometric analysis showed a skeletal class II relationship with a prognathic maxilla, normovergent pattern, and labioversion of maxillary and mandibular incisors (details are shown in Table 1). All third molars were fully erupted and well occluded.

The patient was diagnosed as skeletal class II and dental class I with normovergent pattern, anterior open bite, and proclination of the upper and lower incisors.

The first treatment option was a segmental Le Fort I osteotomy. This procedure can immediately reduce the large amount of posterior vertical dimension and correct two occlusal planes. Since the patient was unable to be hospitalized, he rejected orthognathic surgery under general anesthesia.

The second treatment option was orthodontic intrusion of maxillary teeth using a skeletal anchorage system. A large amount of intrusion of all maxillary teeth except central and lateral incisors was needed for optimal esthetic results in this patient. We thought that miniplates were more suitable than mini-implants because miniplates can be placed apically enough and provide stable intrusive forces. Along with miniplate placement, the supplementary
Table 1 Cephalometric measurements

\begin{tabular}{llll}
\hline Measurement & Pre-treatment & Post-treatment & Post-retention (49 m) \\
\hline SNA & 88.0 & 88.4 & 88.3 \\
SNB & 82.9 & 83.8 & 84.0 \\
ANB & 5.1 & 4.6 & 4.3 \\
Wits & -1.8 & -1.3 & -1.4 \\
SN-MP & 32.3 & 30.7 & 30.8 \\
U1 to SN & 118.9 & 118.1 & 119.3 \\
IMPA & 100.9 & 96.5 & 97.4 \\
Interincisal angle & 107.9 & 114.6 & 112.6 \\
Upper lip E-plane & -0.3 & -0.8 & -1.8 \\
Lower lip E-plane & 5.1 & 4.2 & 4.1 \\
U1-NF & 37.8 & 38.8 & 38.8 \\
U6-NF & 30.5 & 27.0 & 27.4 \\
\hline
\end{tabular}

surgery was considered to reduce the treatment time. A surgical impaction of posterior segments had the advantage of shortening the treatment time and retention of treatment results. Since the patient wanted treatment to end quickly, he agreed to this plan with PMSO and informed consent was obtained.

A fixed tongue crib was delivered to control tongue posture. 0.018-inch standard edgewise brackets were bonded, and 0.0175-inch twisted stainless steel wires were inserted in both arches. Brackets on maxillary canines and premolars were bonded to specially designed position to widen the inter-radicular space, and step bends were added between maxillary canine and premolar to prevent extrusion of anterior teeth.

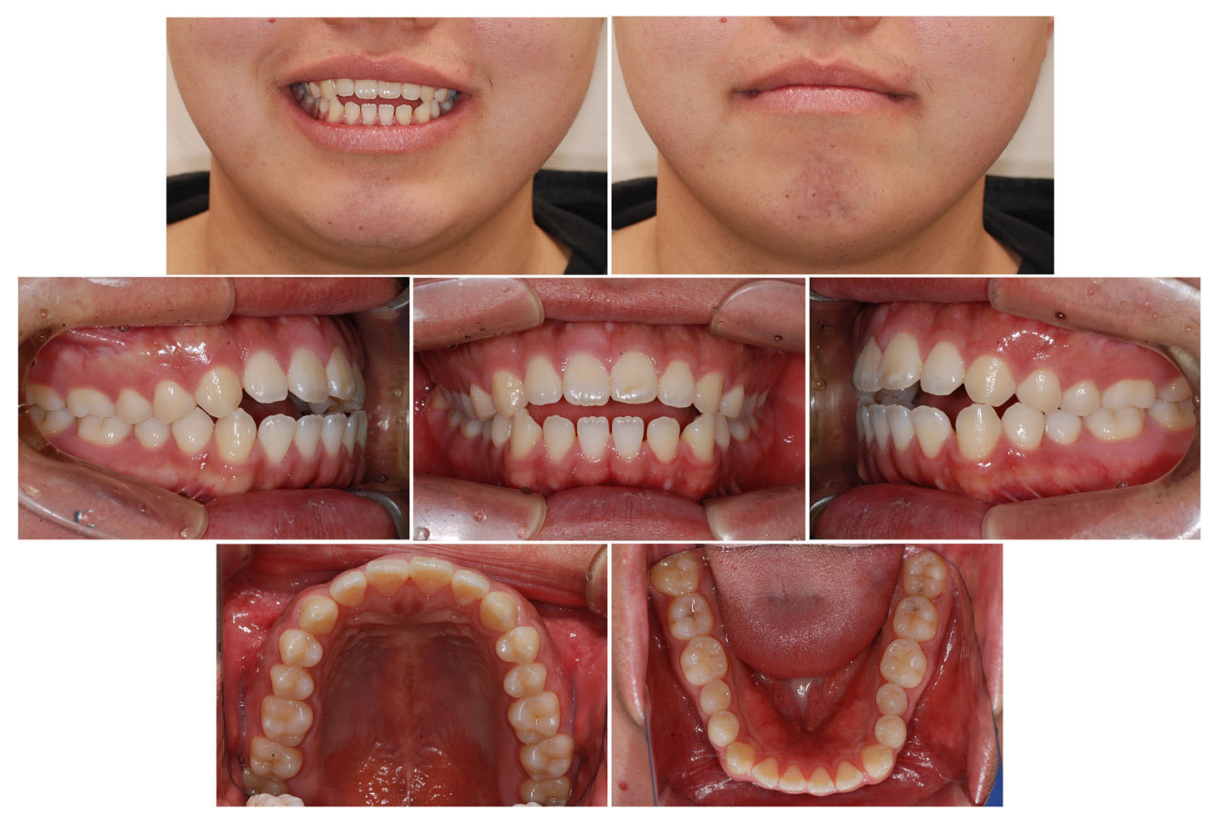

Fig. 1 Pre-treatment photographs 


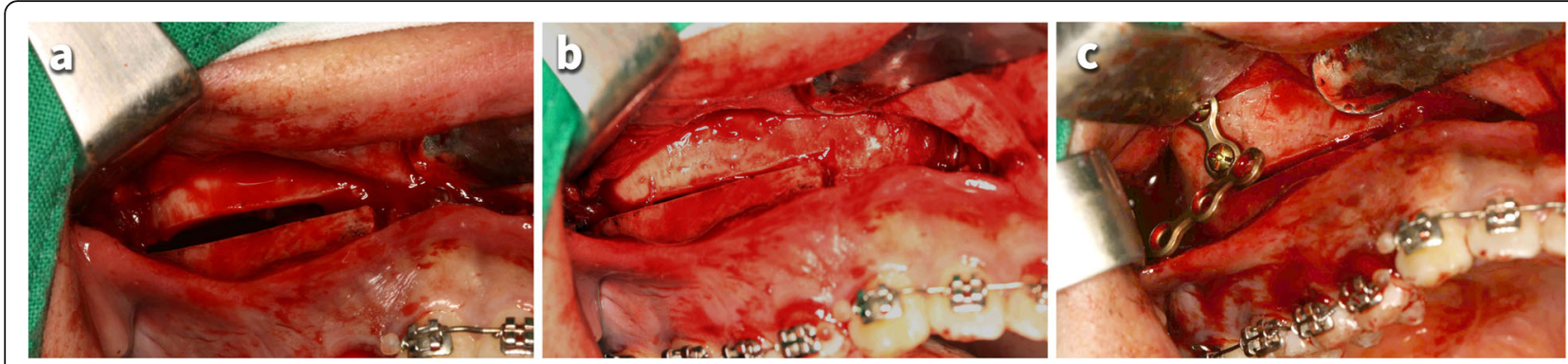

Fig. 2 Intraoperative photographs of posterior maxillary segmental osteotomy (PMSO) and miniplate placement. a Three-mm-wide buccal cortical bone was removed from the horizontal osteotomy line. $\mathbf{b}$ The posterior segment was impacted after the palatal bone cut by curved osteotome. c The miniplate placed on the zygomatic buttress area

Four months later, the wires were changed to 0.016inch stainless steel wires, and open coil springs were inserted between maxillary canines and premolars. After 12 months of alignment, $0.016 \times 0.022$-inch sectional stainless steel wire was inserted in the maxillary arch, and the patient was referred to the Department of Oral and Maxillofacial Surgery for the PMSO.

The surgery was performed under local anesthesia by dividing the left and right sides in consideration of dining convenience (Fig. 2). After full-thickness mucoperiosteal flap was elevated, buccal bone cutting was initiated from inter-radicular space between canine and first premolar, taking care not to damage the root surface. The horizontal cutting was extended to pterygopalatine junction at $5 \mathrm{~mm}$ above the apices of molars. A bone fragment of $3 \mathrm{~mm}$ in width was removed from the horizontal osteotomy line for posterior impaction. The palatal bone was cut by curved osteotome without flap elevation to maintain the blood supply. The bone segment was moved apicolaterally, and T-shaped miniplate was placed on the zygomatic buttress. Posterior teeth were ligated with 0.012-inch dead soft wire to miniplates to hold the bone segment on the place. After surgery, antibiotics and non-steroidal anti-inflammatory drugs were prescribed.

The patient was followed up 2 days after the surgery. Moderate facial swelling and ecchymosis on his maxillary area were identified, but they were relieved after medication and wound irrigation of 2 weeks. A second surgery was performed at the opposite side after a month from the first surgery. The anterior open bite improved immediately after the surgery (Figs. 3 and 4).

A month later from the second surgery, the brackets on maxillary canine were repositioned to normal position, and 0.016-inch nickel-titanium archwire was placed in the maxillary arch. A mini-implant was placed at the center of the mid-palatal suture for further intrusion of posterior teeth. Elastic threads were applied from the lingual button on posterior teeth to mid-palatal mini-implant.

The additional intrusion of posterior teeth was continued for 9 months after the surgery. The maxillary right miniplate was loosened after 6 months from the first surgery, so we replaced it with a new miniplate. The archwires were subsequently changed to 0.014 -inch, 0.016 inch, and $0.016 \times 0.022$-inch stainless steel wire in this

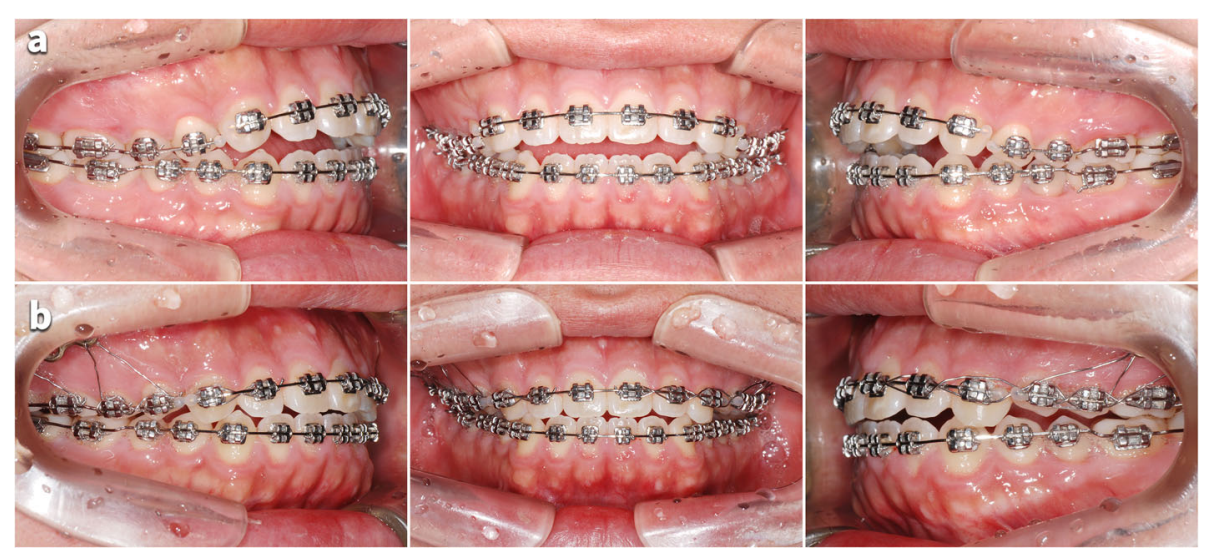

Fig. 3 Occlusal changes after the PMSO. a Before the PMSO. b After the PMSO 


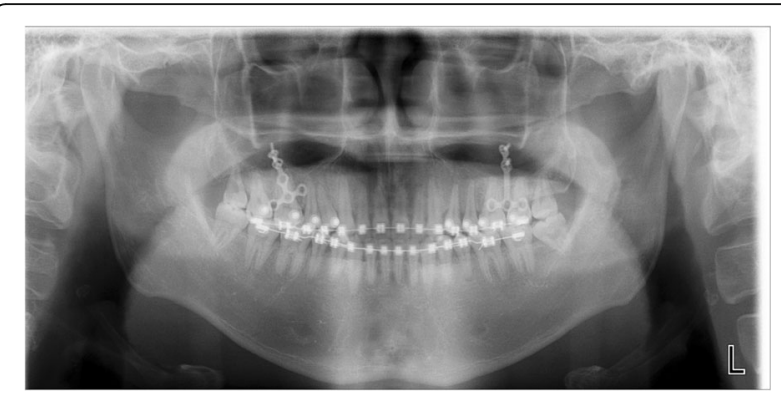

Fig. 4 Post-surgical panoramic radiograph

period. During the finishing stage, the torque of the left maxillary canine and dental midline was corrected.

After 28 months of treatment, a favorable occlusion was obtained, and orthodontic appliances were removed. Fixed retainers were bonded on both arches, and the activator was delivered for retention. A schematic flow of the treatment is shown in Fig. 5.

\section{Treatment results}

Tongue habit was gradually improved with the use of tongue crib and was not recognized after the PMSO surgery.

Facial photographs showed the improvement of the patient's smile esthetics. Reverse smile arc and reverse lip line were corrected to a consonant smile arc and straight lip line, respectively. The exposure of lower teeth in a smile was decreased, and lip competence was achieved without mentalis strain (Fig. 6).

A post-treatment panoramic radiograph showed good root parallelism, and only mild blunting of the apices of the maxillary incisors was seen in the periapical radiograph.

The cephalometric superimposition showed a counterclockwise rotation of the mandible; the SN-MP angle was reduced from 32.3 to 30.7. Single occlusal plane was achieved by $3.5 \mathrm{~mm}$ of the intrusion of the maxillary molars and $1.0 \mathrm{~mm}$ of the extrusion of maxillary incisors. The mandibular molars were extruded by $1.0 \mathrm{~mm}$. At the 49 month retention, treatment results were stable without opening of mandibular plane angle (Fig. 7, Table 1).

\section{Discussion}

The introduction of skeletal anchorages has opened a new ground for the treatment of anterior open bite. Intrusion of the posterior teeth using skeletal anchorages provides more stable and esthetic results than extrusion of anterior teeth. However, the intrusion is one of the slowest movements among the various tooth movements. Therefore, the treatment duration of anterior open bite is mainly dependent on the rate of molar intrusion.

Various methods for the PMSO have been introduced according to the number of operations and the position of the osteotomy [11-13]. In this case, we followed the technique of Tuncer et al. This surgical method has the advantage of maintaining the palatal blood flow by not elevating the palatal flap. In addition, we impacted the posterior segments after removing the buccal cortical bone of $3 \mathrm{~mm}$ in width. To secure sufficient interradicular space, premolar extraction was also considered, but was dismissed because no posterior movement of the incisor was required.

Posterior maxillary segmental osteotomy




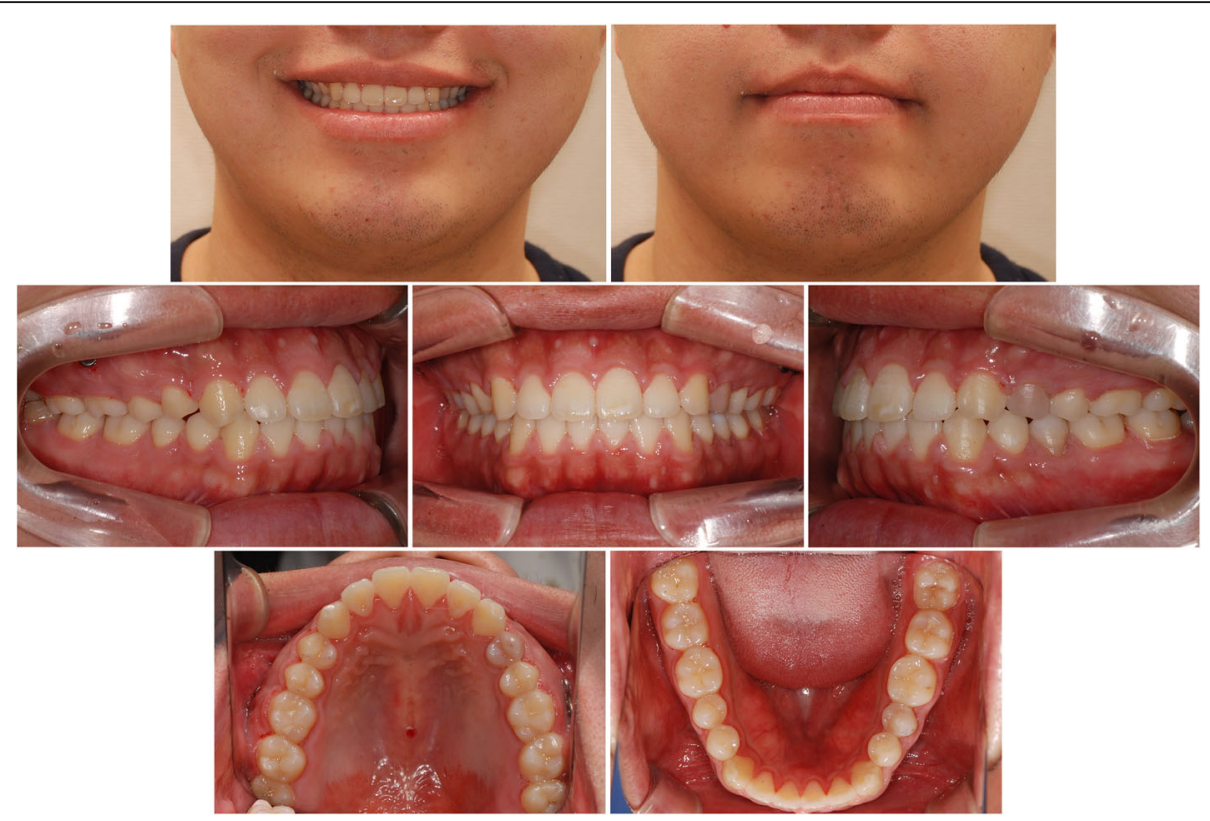

Fig. 6 Post-treatment photographs

Pulp necrosis occurred without apparent root damage on the adjacent tooth to the osteotomy line. Pink discoloration of right maxillary first premolar was recognized 8 months from the surgery. At that time, the patient did not have any symptoms. After 14 months, however, he complained of pain during occlusion and tenderness to percussion on this tooth. It was diagnosed as pulp necrosis, and root canal treatment was performed. Many retrospective studies reported the prevalence of the pulp necrosis after Le Fort I osteotomy ranging 0.5 to $3.4 \%$
[14-17]. Lownie et al. reported that ischemic stress induced by surgical procedures could result in inflammatory changes in pulp tissue, and there were degenerative changes with vacuolization and atrophy of the odontoblastic layer [18]. The study using laser Doppler flowmetry showed that the segmental Le Fort I surgery induced a decrease of pulpal blood flow in adjacent to vertical osteotomy line [19]. In this case, osteotomy performed on a narrow inter-radicular space appears to have affected the pulpal blood supply.
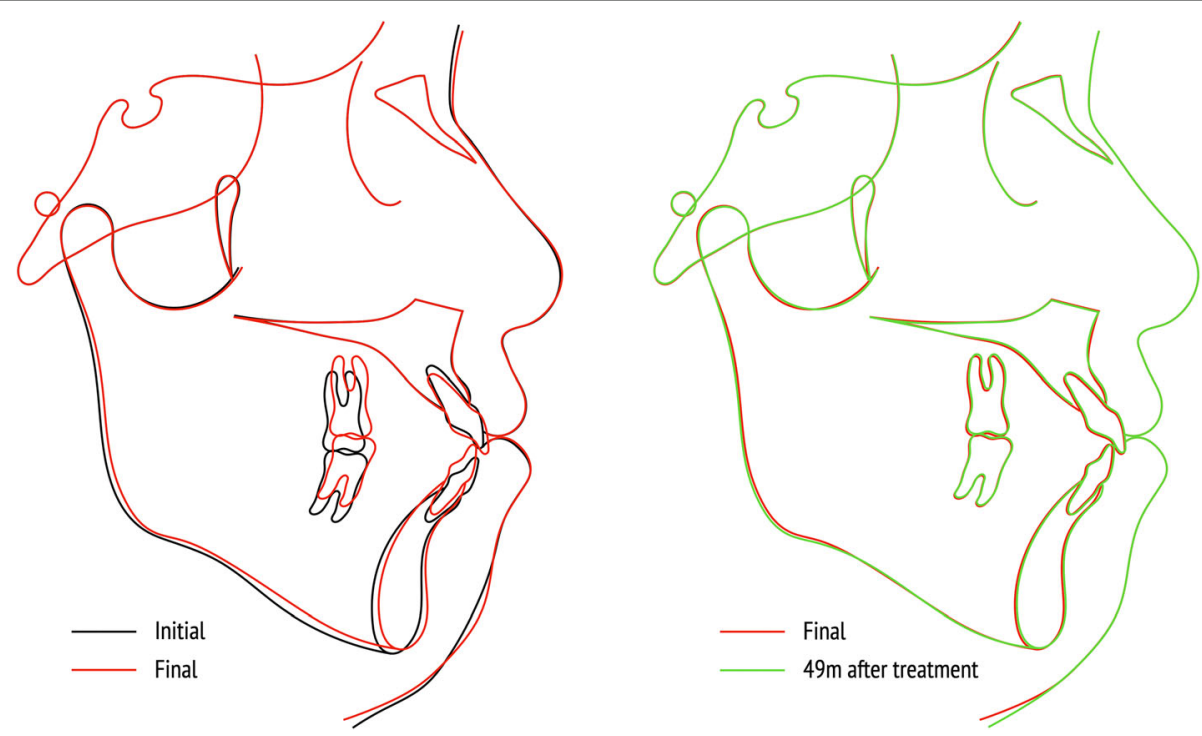

Fig. 7 Superimposition of the cephalometric tracing. Black line, before treatment; red line, after treatment (28 months after initiation of orthodontic treatment); green line, retention after 49 months 

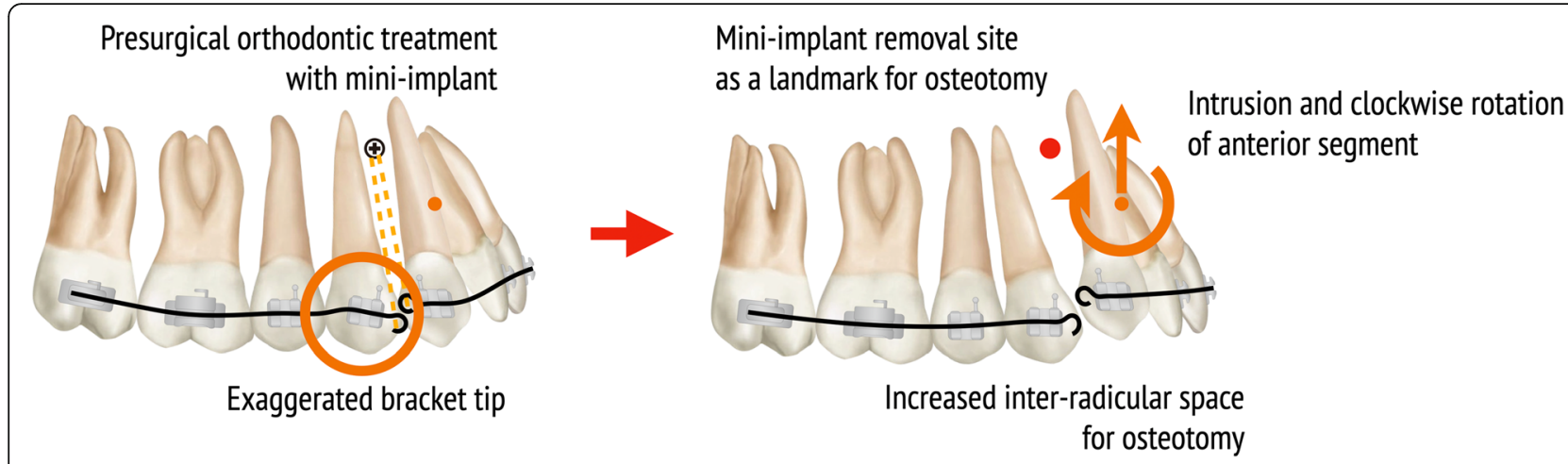

Fig. 8 Orthodontic strategy to avoid root damage during PMSO

A sufficient impaction of posterior teeth was achieved by PMSO surgery, but the premature contacts on the canines prevented further closure of the mandible (Fig. 3). Considerable time was spent for intruding canines after PMSO surgery, and small amount of extrusion of mandibular posterior teeth occurred during this time. If we had actively intruded the maxillary canines using miniimplants before the PMSO surgery, post-surgical orthodontic treatment would have been shortened. To reduce the risk of root damage and shorten the treatment period, it is helpful to actively intrude the anterior segment by using a mini-implant and to improve the axis of the canine and premolar in pre-surgical orthodontic treatment (Fig. 8).

In this case, since the patient mainly had vertical problems including anterior open bite and long lower facial height, the impaction of the posterior teeth was the main focus in the treatment plan. The impaction of the through PMSO was judged to be advantageous compared to orthodontic intrusion because all the teeth except the incisors were occluded. Functional occlusion and improvement of facial esthetics were obtained through orthodontic treatment including PMSO, and this treatment results have been maintained over 4 years.

\section{Conclusion}

The impaction of the posterior dentoalveolar segment using PMSO can be a good treatment option in patients with anterior open bite showing two occlusal planes. In order to reduce side effects and increase treatment efficiency, planned orthodontic movement must be performed in the pre-surgical orthodontic treatment, as with orthognathic surgery.

\section{Acknowledgements}

No acknowledgement

\section{Authors' contributions}

SKC drafted the manuscript and critically revised the manuscript. KHK participated in the study design and coordination and helped to draft the manuscript. All authors read and approved the final manuscript.
Funding

No funding source.

\section{Availability of data and materials}

Not applicable (data sharing not applicable to this article as no datasets were generated or analyzed during the current study).

\section{Ethics approval and consent to participate}

This study was conducted after approval from the Institutional Review Board of Wonkwang University Dental Hospital (IRB no. WKDIRB202004-01), and the informed consent was waived.

\section{Consent for publication}

Written informed consent was obtained from the patient for the publication of this report and any accompanying images.

\section{Competing interests}

The authors declare that they have no competing interests.

\section{Author details}

${ }^{1}$ College of Dentistry, Graduate School of Wonkwang University, Muwanglo 895, Iksan, Jeonlabookdo, Republic of Korea. ${ }^{2}$ Department of Oral and Maxillofacial Surgery, College of Dentistry, Wonkwang University, Iksan, Republic of Korea.

Received: 11 May 2020 Accepted: 3 June 2020

Published online: 15 June 2020

\section{References}

1. Mizrahi E (1978) A review of anterior open bite. Br J Orthod 5(1):21-27

2. Kim Y-H (1987) Anterior openbite and its treatment with multiloop edgewise archwire. Angle Orthod 57(4):290-321

3. Rijpstra C, Lisson JA (2016) Etiology of anterior open bite: a review. J Orofac Orthop 77(4):281-286

4. Cangialosi TJ (1984) Skeletal morphologic features of anterior open bite. Am J Orthod 85(1):28-36

5. Xun C, Zeng X, Wang X (2007) Microscrew anchorage in skeletal anterior open-bite treatment. Angle Orthod 77(1):47-56

6. Baek M-S, Choi Y-J, Yu H-S, Lee K-J, Jinny K, Park Y-C (2010) Long-term stability of anterior open-bite treatment by intrusion of maxillary posterior teeth. Am J Orthod Dentofac Orthop 138(4):396.e1-396.e9

7. Greenlee GM, Huang GJ, Chen SSH, Chen J, Koepsell T, Hujoel P (2011) Stability of treatment for anterior open-bite malocclusion: a meta-analysis. Am J Orthod Dentofac Orthop 139(2):154-169

8. Marzouk ES, Kassem HE (2016) Evaluation of long-term stability of skeletal anterior open bite correction in adults treated with maxillary posterior segment intrusion using zygomatic miniplates. Am J Orthod Dentofac Orthop 150(1):78-88

9. Hwang J-H, Jung B-Y, Lim C-S, Cha I-H, Park W-S (2011) Posterior maxillary segmental osteotomy concomitant with sinus lift using a piezoelectric device. J Oral Maxillofac Surg 69(9):2339-2344 
10. Basa S, Varol A, Sener ID, Sertgoz A (2008) Posterior maxillary segmental osteotomy for restoring the mandible with dental implants: a clinical report. J Prosthet Dent 99(5):340-343

11. Esteves LS, Santos JN, Sullivan SM, Martins LM, Ávila C (2016) Why segment the maxilla between laterals and canines? Dental Press J Orthod 21:110-125

12. Kahnberg KE, Hagberg C (2007) The approach to dentofacial skeletal deformities using a multisegmentation technique. Clin Plast Surg 34(3):477-484

13. Tuncer C, Ataç MS, Tuncer BB, Kaan E (2008) Osteotomy assisted maxillary posterior impaction with miniplate anchorage. Angle Orthod 78(4):737-744

14. Vedtofte P, Nattestad A (1989) Pulp sensibility and pulp necrosis after Le fort I osteotomy. J Craniomaxillofac Surg 17(4):167-171

15. Mesgarzadeh A, Motamedi MH, Akhavan H, Tousi TS, Mehrvarzfar P, Eshkevari PS (2010) Effects of Le fort I osteotomy on maxillary anterior teeth: a 5-year follow up of 42 cases. Eplasty 10:e10-e10

16. Lee U-L, Lee E-J, Seo H-Y, Han S-H, Choi W-C, Choi Y-J (2016) Prevalence and risk factors of tooth discolouration after orthognathic surgery: a retrospective study of 1455 patients. Int J Oral Maxillofac Surg 45(11):1464-1470

17. Ho MW, Boyle MA, Cooper JC, Dodd MD, Richardson D (2011) Surgical complications of segmental Le fort I osteotomy. Br J Oral Maxillofac Surg 49(7):562-566

18. Lownie JF, Cleaton-Jones PE, Coleman H, Forbes M (1999) Long-term histologic changes in the dental pulp after posterior segmental osteotomies. Oral Surg Oral Med Oral Pathol Oral Radiol Endod 87(3):299-304

19. Emshoff R, Kranewitter R, Gerhard S, Norer B, Hell B (2000) Effect of segmental Le fort I osteotomy on maxillary tooth typerelated pulpal blood-flow characteristics. Oral Surg Oral Med Oral Pathol Oral Radiol Endod 89(6):749-752

\section{Publisher's Note}

Springer Nature remains neutral with regard to jurisdictional claims in published maps and institutional affiliations.

\section{Submit your manuscript to a SpringerOpen ${ }^{\circ}$ journal and benefit from:}

- Convenient online submission

- Rigorous peer review

- Open access: articles freely available online

- High visibility within the field

- Retaining the copyright to your article

Submit your next manuscript at $\boldsymbol{\nabla}$ springeropen.com 